\title{
Evaluation of various membrane filtration modules for the treatment of seawater
}

\author{
Hisham A. Maddah ${ }^{1}$ (1) $\cdot$ Abdulazez S. Alzhrani $^{1} \cdot$ M. Bassyouni ${ }^{1,2} \cdot$ M. H. Abdel-Aziz ${ }^{1,3} \cdot$ Mohamed Zoromba $^{1,4}$. \\ Ahmed M. Almalki ${ }^{1}$
}

Received: 14 September 2017 / Accepted: 28 August 2018 / Published online: 4 September 2018

(c) The Author(s) 2018

\begin{abstract}
This study was initiated to identify the treatment efficiency of various membrane filtration modules in the treatment of Red Sea water at Rabigh City. Filtration efficiency (membrane performance) was calculated in terms of water conductivities of feed and product. Four commercial membranes were utilized in the experiment work and they were Polyvinylidene difluoride (FP100), Polyethersulphone (ES404), Polyamide low-pressure film (AFC40) and Polyamide high-pressure film (AFC99). Different pressure values were applied on each membrane type to determine the optimal operating pressure for the treatment. $\mathrm{pH}$ levels of produced water were analyzed relative to feed water $\mathrm{pH}$ to check the effect of different applied pressures on $\mathrm{pH}$ variations. A comparison between the four membranes was established to select the ideal membrane for the treatment. Results showed that the optimal operating pressures for the four membranes FP100, ES404, AFC40 and AFC99 were 10, 30, 60 and 64 bar, respectively. In general, applying higher pressures would increase the treatment efficiency. An inverse relationship between water conductivity and applied pressure was noted, and $\mathrm{pH}$ levels slightly decreased at high pressures. Among the four selected membranes, AFC40 was the ideal choice for water treatment due to its relatively lower energy demand and higher treatment efficiency of $99.9 \%$.
\end{abstract}

Keywords Membrane $\cdot$ Filtration $\cdot$ Conductivity $\cdot$ Water treatment $\cdot$ Desalination $\cdot$ TDS $\cdot$ Seawater

\section{Introduction}

Recently, membrane filtration techniques have become more attractive in desalination applications for the production of potable water due to its lower capital costs compared to other treatment processes. Membranes can separate pollutants

Electronic supplementary material The online version of this article (https://doi.org/10.1007/s13201-018-0793-8) contains supplementary material, which is available to authorized users.

Hisham A. Maddah

hmaddah@kau.edu.sa

1 Department of Chemical Engineering, King Abdulaziz University, Rabigh, Saudi Arabia

2 Department of Chemical Engineering, Port Said University, Port Fouad, Egypt

3 Department of Chemical Engineering, Alexandria University, Alexandria, Egypt

4 Department of Chemistry, Port Said University, Port Said, Egypt from seawater easily and this is achieved by passing water through polymer films of various shapes (e.g. tubular and flat sheet) while preventing contaminants on the other side of the membrane (National Environmental Services Center 1999).

Seawater desalination becomes very important for the production of fresh water in many countries around the globe (Alawadhi 2002). In 2004, the IDA Desalting Inventory reported that around 75 million people in the world get fresh water from desalination plants in which either seawater or brackish water is desalinated (Inventory 2004). The worldwide capacity of desalination plants is approximately 40 million $\mathrm{m}^{3} /$ day whereas the annual average growth rate for desalination in the last 5 years is 12\% (Profile 2006).

Seawater desalination is considered the most energy intensive technique compared to conventional technologies for the treatment of fresh water. Research advancements and successful practices in desalination technologies assured the feasibility and sustainability of desalination for drinking water supply. Traditional seawater and brackish water desalination processes include multi effect distillation (MED), multi stage flash (MSF), reverse osmosis (RO) and 
electrodialysis (ED) (Van der Bruggen and Vandecasteele 2002).

MED process is the first discovered desalination technology which depends on the heat transferred from condensation of steam to seawater or brine in a series of stages. However, corrosion and scaling of Calcium Sulfate $\left(\mathrm{CaSO}_{4}\right)$ are very common problem in MED (Van der Bruggen and Vandecasteele 2002).

In 1960s, MSF technology became the most common desalination process for various decades. The reason behind this is that MSF operation is simple and reliable since its principle relies only on a series of flash chambers which generate steam from saline feedwater that is condensed in further stages for the removal of salt and collection of fresh water. MSF corrosion related problems are much less that MED and can be easily controlled due to the simplicity of MSF design (Van der Bruggen and Vandecasteele 2002).

$\mathrm{RO}$ is a pressure-driven process that separates salt from seawater across a semi-permeable membrane by applying a pressure larger than the osmotic pressure. Fresh water flux rate is proportional to the applied pressure differential; meaning that higher applied pressure increases RO production. Operating pressure in RO plants ranges from 15 to 30 bar for brackish water and from 55 to 70 bar for seawater desalination. Today, RO is the most successful commercial process for the production of large quantities of fresh water from seawater. Even though RO is the most efficient commercial desalination process, $\mathrm{RO}$ requires high electric energy of about $3-10 \mathrm{kWh} / \mathrm{m}^{3}$ of fresh water produced from seawater. The energy required for the initial pressurization of the feed water in RO modules is a setback and should be investigated furtherly. RO plants have high water recoveries from 25 to $45 \%$ for seawater and up to $90 \%$ for brackish water (Charcosset 2009).

ED process removes salts from seawater or brackish water by passing water through a stack of cationic and anionic membranes with an applied electric potential, so that a diluted stream is obtained. Even though the expected breakthrough of ED has never been realised, it is still the next most promising technique for water treatment after RO (Van der Bruggen and Vandecasteele 2002).

In seawater desalination, MSF is accounted for 52.8\% whereas RO membrane filtration technology is accounted for $41.1 \%$ (Humplik et al. 2011). It should be noted that MSF holds the lead in all plants producing over $5000 \mathrm{~m}^{3} /$ day units (Inventory 2004). MSF technology is presently moving towards very large unit sizes and has reached the $75,850 \mathrm{~m}^{3} /$ day unit size at Shuweiat project in UAE. Large MSF units reduces water production costs compared to small scale units. The maximum production capacity of a RO train size can reach up to $9084-13,626 \mathrm{~m}^{3} /$ day which is far off from a MSF unit size of $56,775-68,130 \mathrm{~m}^{3} /$ day (Khawaji et al. 2008). However, according to IDA Desalination Yearbook
2016-2017, membrane desalination technologies accounted for more than $90 \%$ of all desalination plants. Sagle and Freeman (2004) reported that production of desalinated water by RO is much cheaper than MSF which indicates that desalination by RO is a more logical and economical option; water costs comparison between different desalination processes are shown in Table 1 (Sagle and Freeman 2004). Furthermore, another study by Van der Bruggen and Vandecasteele (2002) showed that producing water by reverse osmosis has a much lower cost than MSF and multi-effect distillation (MED). It was reported that the water cost by RO is around $0.5-0.7 \$ / \mathrm{m}^{3}$ where MSF and MED production cost is about $1-1.4 \$ / \mathrm{m}^{3}$ depending on the energy cost in the plant (Van der Bruggen and Vandecasteele 2002; Wade 1993; Malek et al. 1996). A comparison between several RO plants has been investigated by the authors from previous reported data in order to determine the relation between water production capacity and water price as illustrated in Fig. 1 (Greenlee et al. 2009).

The implementation of hybrid processes in seawater desalination would improve reverse osmosis desalination process and ensure a sustainable production of drinking water on long terms. Having a pretreatment process to RO membranes by microfiltration (MF), ultrafiltration (UF) or nanofiltration (NF) would prevent any fouling issues contributing to the cost effectiveness of the desalination process (Drioli et al. 2002; Van der Bruggen and Vandecasteele 2002). A previous work showed that NF membrane can be used as a pretreatment for the RO membrane to produce high quality water (Alzahrani et al. 2013). Truby (2000) confirmed that there is a relation between the use of a hybrid process (pretreatment) and water production cost by showing that UF pretreatment could increase the RO flux by $20 \%$ which resulted in a significant reduction of RO capital costs.

It is commercially common to combine RO with another distillation plant process such as MSF, MED or NF/MF. Hybrid processes allow for more reliable and established processes with greater flexibility and the advantage of generating both water and electricity at the same plant. Combining $\mathrm{RO}$ with a NF/MF module (placed before RO) is a great pretreatment choice in membrane desalination plants to prevent corrosion in distillation processes and fouling in RO units.

Table 1 Energy and water costs of various desalination processes

\begin{tabular}{lll}
\hline Desalination process & Unit energy cost $\left(\$ / \mathrm{m}^{3}\right)^{\mathrm{a}}$ & $\begin{array}{l}\text { Water } \\
\text { cost }(\$ / \\
\left.\mathrm{m}^{3}\right)^{\mathrm{a}}\end{array}$ \\
\hline MSF & 1.1 & 1.04 \\
MED & 1.15 & 0.95 \\
RO & 0.63 & 0.82 \\
\hline
\end{tabular}

${ }^{\text {a These calculations are based on a plant capacity of } 31,822 \mathrm{~m}^{3} / \text { day }}$ and a TDS concentration of $37,000 \mathrm{mg} / \mathrm{L}$ 
Fig. 1 RO production capacity versus water price for different RO plants

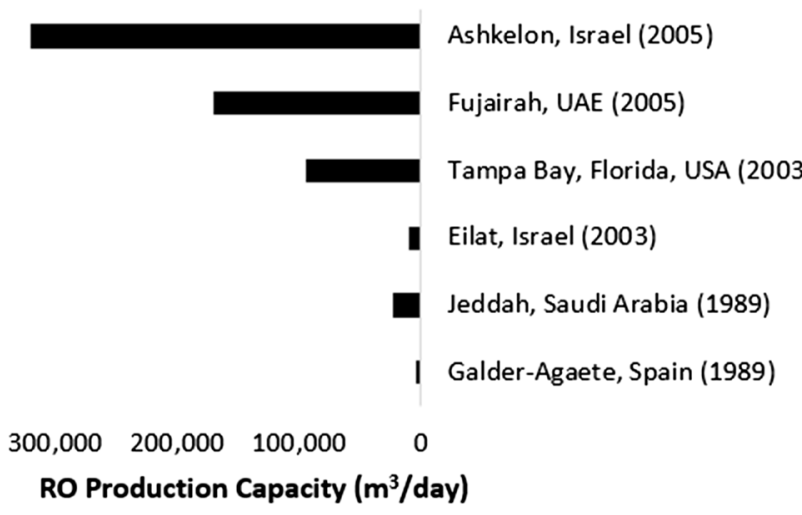

This integration and synergy contributes to the cost effectiveness of the desalination process by extending the lifetime of RO units and ensuring a sustainable long-term production of drinking water in arid regions (Van der Bruggen and Vandecasteele 2002). Multi-stage RO (MSRO) combines RO and nanofiltration (NF) stages in series to increase the water recovery and protect the RO module while achieving high rejections. For example, a desalination process of one RO and two NF stages in series can achieve a $65 \%$ water recovery and produce a fresh water with $350 \mathrm{ppm}$ when seawater feed concentration is 35,000 ppm (Ahunbay et al. 2018).

Desalination membrane processes like RO and ED can also be coupled with renewable energies such as solar, wind, wave, and hydrostatic pressure in order to reduce the estimated cost of produced potable water (Charcosset 2009). Khaydarov and Khaydarov (2007) proposed a solar-powered RO unit which does not require an external energy source for pumping feed water; the proposed $\mathrm{RO}$-solar system reduced the RO specific power consumption for seawater treatment from 5 to $1 \mathrm{kWh} / \mathrm{m}^{3}$.

A membrane can be defined as a thin layer of semi-permeable material that is able to separate substances by applying a driving force across the membrane. The ultimate goal of membrane filtration processes is to remove contaminants such as salt, bacteria, microorganisms, particulates, and natural organic material from a solvent that is usually water (National Environmental Services Center 1999). Membrane processes can be categorized into pressure-driven, solute-transfer, thermal and hybrid processes as shown in Table 2 (Fane 1996).

The technologies included in membrane filtration are MF, UF, NF and RO. Microfiltration (MF) is a membrane separation process for separating large molecular weight suspended or colloidal compounds from dissolved solids at moderate low feed water operating pressure that is about 1-6.2 bar with a pore size between 0.1 and $10 \mu \mathrm{m}$. However, ultrafiltration (UF) membrane process is a selective separation step used to both concentrate and purify medium to high molecular weight components which occurred under operating pressure of approximately $1-10$ bar with a pore size between 0.01 and $0.1 \mu \mathrm{m}$. Nanofiltration (NF) membranes have a smaller pore size compared to MF and UF that is approximately 0.001 micron and it is designed to achieve highly specific separation of low molecular weight compounds. Thus, a higher operating pressure is required in NF membranes in order to push water through these smaller pores which is usually near 20-40 bar. As a result, NF membranes requires more energy than MF or UF. However, reverse osmosis (RO) is the most advanced membrane type that has smaller pore size than NF membrane (less than $0.001 \mu \mathrm{m}$ ) with high operating pressure that is about 30-100 bar which can effectively remove nearly all inorganic pollutants (up to $99 \%$ of salts) from water (Wagner 2001; EPA 2005; Maddah and Chogle 2015; GEA Process Engineering Inc. 2012; Emis 2010; Smart Membrane Solutions 2002). In terms of organic compounds, RO membranes are less effective for the treatment of organics and with a potential of having a biofouling problem.

Table 2 Various membrane processes for water treatment

\begin{tabular}{lll}
\hline Membrane process & Mechanism & Examples \\
\hline $\begin{array}{l}\text { Pressure-driven } \\
\text { Thermal }\end{array}$ & Contaminants are removed by various mechanisms depending on pore size & MF, UF, NF, RO \\
Hybrid & Liquid water undergoes phase change as it passes the membrane (requires heat) & MD, PV \\
& $\begin{array}{l}\text { Membrane process is coupled with another unit process such as pretreatment, adsorption, } \\
\text { ion exchange or coagulation }\end{array}$ & - \\
\hline
\end{tabular}

$M D$ membrane distillation, $P V$ photovoltaic 
Table 3 Various membrane processes for water treatment

\begin{tabular}{|c|c|c|c|}
\hline Membrane type & Ideal separation processes & Common applications & References \\
\hline Microfiltration (MF) & Pretreatment processes & $\begin{array}{l}\text { Cell harvesting from fermentation broths, frac- } \\
\text { tionation of milk proteins, corn syrup clarifica- } \\
\text { tion and CIP chemical recovery }\end{array}$ & $\begin{array}{l}\text { GEA Process } \\
\text { Engineering } \\
\text { Inc. }(2012)\end{array}$ \\
\hline Ultrafiltration (UF) & Dairy proteins, carbohydrates and enzymes & $\begin{array}{l}\text { Whey protein concentration, gelatin de-ashing } \\
\text { and concentration, and clarification of fruit } \\
\text { juices. }\end{array}$ & \\
\hline Nanofiltration (NF) & Minerals and salts from complex process streams & $\begin{array}{l}\text { De-ashing of dairy products, recovery of hydro- } \\
\text { lyzed proteins, concentration of sugars and } \\
\text { purification of soluble dyes and pigments }\end{array}$ & \\
\hline Reverse osmosis (RO) & $\begin{array}{l}\text { De-watering process streams, concentration of } \\
\text { low molecular weight compounds or clean-up } \\
\text { of waste effluents }\end{array}$ & $\begin{array}{l}\text { Preconcentration of dairy or food streams prior to } \\
\text { evaporation, polishing of evaporator conden- } \\
\text { sate, and purification of process water }\end{array}$ & \\
\hline
\end{tabular}

Rajamohan et al. (2014) carried out an experimental study on the removal of total organic carbon and trihalomethane (THM) from drinking waters and determined that RO membranes removed $83.8 \%$ of THM. Another study identified the rejection for organic compounds by RO is over $75 \%$ (Yoon and Lueptow 2005). Moreover, ultra-low pressure reverse osmosis (ULPRO) membrane is found to be very effective in the removal of organics from surface water and wastewater with an observed rejection of over $90 \%$ when the molecular weight is more than 150 . The removal efficiency increases linearly with the molecular weight as well as with the molecular width and depends on the feed $\mathrm{pH}$ (Ozaki and Li 2002). As mentioned, treatment of organics would result in biofouling issues depending on the amount of organic matter and colloidal particles in the feed water. Biofouling occurs when dissolved organics deposits on the membrane surface leading to an increase in the overall membrane resistance and therefore eliminating organics in a pretreatment process (e.g. ozonation-membrane process) is mandatory to protect the RO module (Maddah and Chogle 2017; Williams et al. 1990).

The use of RO membranes in series with multiple units is very effective and recommended for the treatment of high salinity water (sea water) because series organization allows us to have better recovery and higher rejection rates (Wagner 2001; EPA 2005; Maddah and Chogle 2015; GEA Process Engineering Inc. 2012; Emis 2010; Smart Membrane Solutions 2002). Ideal separation processes and common applications of the different membrane types are summarized in Table 3 (GEA Process Engineering Inc. 2012). Table 4 and Fig. 2 shows the range of nominal membrane pore sizes of the different discussed membranes (Wagner 2001; EPA 2005; Maddah and Chogle 2015; GEA Process Engineering Inc. 2012; Emis 2010; Smart Membrane Solutions 2002).

In $\mathrm{RO}$, an external pressure that is greater than the osmotic pressure on the seawater is applied in order to let the water flows from the salt solution to the pure waterside. Therefore, RO membrane will reject most of the dissolved
Table 4 Typical pore size and operating pressure of various membrane types (Wagner 2001; EPA 2005; Maddah and Chogle 2015; GEA Process Engineering Inc. 2012; Emis 2010; Smart Membrane Solutions 2002)

\begin{tabular}{lcc}
\hline Membrane type & Pore size $(\mu \mathrm{m})$ & $\begin{array}{l}\text { Operating } \\
\text { pressure } \\
\text { (bar) }\end{array}$ \\
\hline Microfiltration (MF) & $0.1-10(1-1000 \mathrm{~nm})$ & $1-6.2$ \\
Ultrafiltration (UF) & $0.01-0.1(1-100 \mathrm{~nm})$ & $1-10$ \\
Nanofiltration (NF) & $0.001(1 \mathrm{~nm})$ & $20-40$ \\
Reverse osmosis (RO) & $<0.001(<1 \mathrm{~nm})$ & $30-100$ \\
\hline
\end{tabular}

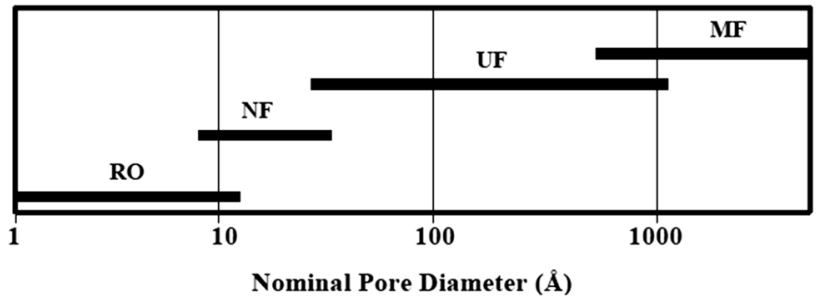

Fig. 2 Typical pore diameter of different membranes (Sagle and Freeman 2004)

salts and produce treated water (Van der Bruggen and Vandecasteele 2002; Wijmans and Baker 1995; Khawaji et al. 2008). It is worth mentioning that any RO desalination plant must contain four major components and they are feed water pre-treatment, high pressure pumping, membrane separation, and permeate post-treatment (Ayyash et al. 1994; Al-Badawi et al. 1995; Nada et al. 1995; Badrulla Baig et al. 1999). Typically, pretreatment to RO or NF is achieved by placing an MF membrane before them to reduce fouling potential. $\mathrm{RO}$ or NF membranes are ideal to remove both salt and hardness from groundwater as well as seawater (National Environmental Services Center 1999). 
There are different kinds of materials are used to construct MF and UF membranes and they include cellulose acetate, polyvinylidene fluoride, polyacrylonitrile, polypropylene, polysulfone, polyethersulfone, or other polymers. Characteristics and properties of each membrane vary based on the used material which may affect on the surface charge, degree of hydrophobicity, $\mathrm{pH}$ and oxidant tolerance, strength and flexibility of the membrane. On the other hand, cellulose acetate or ployamide materials are the main components in manufacturing NF and RO membranes. In fact, cellulose membranes must be operated within a narrow $\mathrm{pH}$ range of 4-8 to avoid membrane biodegradation (National Environmental Services Center 1999).

Water flux within the membrane can be calculated from Eq. (1) with the assumption that there is no fouling effect and we have only the membrane resistance. Inserting Eq. (1) into Eq. (2); will give us Eq. (3) (SOLTEQ Company: Solution Engineering 2008).

$J=\frac{\Delta P}{v R_{\mathrm{m}}}$

$J=k \ln \left[\frac{C_{\mathrm{w}}}{C_{\mathrm{b}}}\right]$

$\ln \left[\frac{C_{\mathrm{w}}}{C_{\mathrm{b}}}\right]=\frac{\Delta P}{v R_{\mathrm{m}} k}$

where $J$ is the water flux; $P$ is the differential operating pressure; $v$ is the water volume; $R_{\mathrm{m}}$ is the membrane resistance; $C_{\mathrm{w}}$ is the solute concentration; $C_{\mathrm{b}}$ is the bulk-solute concentration and $k$ is the proportionality constant (SOLTEQ Company: Solution Engineering 2008).

Equation (2) shows that there is a proportional relationship between the water flux and the dimensionless concentration of water contaminations near to the membrane surface where $k$ is the proportionality constant. Also, Eq. (3) illustrates that higher applied pressure and less membrane resistance are the favoured conditions for achieving higher concentration gradients; thereby higher flux rates. In other words, higher applied pressures increase the dimensionless concentration of water logarithmically (very slowly). Considering the membrane wall at the permeate side, our experimental work shows this phenomenon is true as lower water conductivities are observed at the bulk-phase. Figure 3 shows the difference between (the solute concentration near to the membrane wall) and (the bulk-solute concentration). It is obvious that as we go far away from the membrane surface, salt concentration decreases until we reach the bulk solute concentration, and this is attributed to concentration polarization phenomenon.

The objective of this study is to determine the treatment efficiency of various commercial membrane filtration

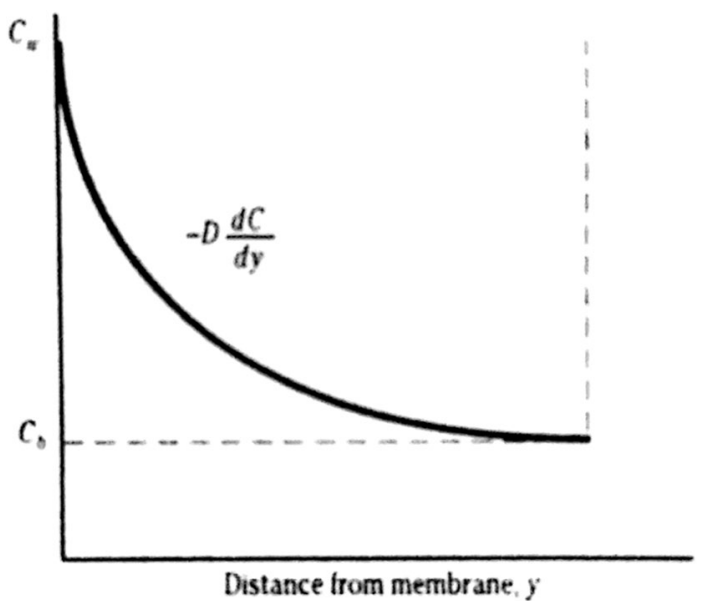

Fig. 3 Concentration polarization at the membrane surface (SOLTEQ Company: Solution Engineering 2008)

Table 5 Ion composition of collected Red Sea water at Rabigh City (Greenlee et al. 2009; Lenntech 2005)

\begin{tabular}{ll}
\hline Ion $($ chemical symbol) & Concentration $(\mathrm{mg} / / \mathrm{L})$ \\
\hline Chloride $\left(\mathrm{Cl}^{-}\right)$ & 22,219 \\
Sodium $\left(\mathrm{Na}^{+}\right)$ & 14,255 \\
Sulfate $\left(\mathrm{SO}_{4}{ }^{2-}\right)$ & 3078 \\
Magnesium $\left(\mathrm{Mg}^{2+}\right)$ & 742 \\
Calcium $\left(\mathrm{Ca}^{2+}\right)$ & 255 \\
Potassium $\left(\mathrm{K}^{+}\right)$ & 210 \\
Bicarbonate $\left(\mathrm{HCO}_{3}^{-}\right)$ & 146 \\
Bromide $\left(\mathrm{Br}^{-}\right)$ & 72 \\
Total dissolved solids (TDS) & $41,000-42,000$ \\
\hline
\end{tabular}

modules (ITT PCI Membranes Ltd) for the treatment of Red Sea water at Rabigh City. Four commercial ITT PCI membranes were utilized in the experiment work and they were Polyvinylidene difluoride (FP100), Polyethersulphone (ES404), Polyamide low-pressure film (AFC40) and Polyamide high-pressure film (AFC99). Effect of applied pressure on the membrane performance has been investigated to obtain the optimal operating pressure for every studied membrane as well as the highest performance. $\mathrm{pH}$ levels of produced water were analyzed relative to feed water $\mathrm{pH}$ to check the effect of different applied pressures on $\mathrm{pH}$ variations. A comparison between the four membranes was established to select the ideal membrane for the treatment.

\section{Methodology and experiment}

Water samples from the Red Sea water at Rabigh City have been taken as a feed in the experiment work for further investigations. Major ion composition of collected seawater

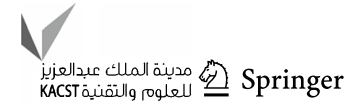


Table 6 Physical properties of the four commercial membrane types ${ }^{\mathrm{a}}$ (ITT PCI Membranes Ltd 2011; Khulbe et al. 2007; Otero et al. 2008)

\begin{tabular}{llllllll}
\hline$\#$ & Type of membrane & $\begin{array}{l}\text { Applicable } \\
\text { module }\end{array}$ & Area $\left(\mathrm{m}^{2}\right)$ & Length $(\mathrm{m})$ & $\begin{array}{l}\text { Inner diam- } \\
\text { eter }(\mathrm{mm})\end{array}$ & Pore size; radius $(\mathrm{nm})^{\mathrm{b}}$ & $\begin{array}{l}\text { MWCO (Dalton); } \\
\text { apparent retention } \\
(\%)\end{array}$ \\
\hline 1 & FP100 & UF & 0.9 & 1.2 & 100 & $1-1000$ & $100 \mathrm{kDa}$ \\
2 & ES404 & NF & 2.5 & 0.9 & 210 & $0.65 \pm 0.19$ & $4000 \mathrm{Da}$ \\
3 & AFC40 & RO & 0.9 & 1.2 & 100 & $0.44 \pm 0.07$ & $>60 \% \mathrm{CaCl}_{2}$ \\
4 & AFC99 & RO & 0.9 & 1.2 & 100 & $<1$ & $>99 \% \mathrm{NaCl}$ \\
\hline
\end{tabular}

a Retention depends on several parameters, including nature of the test solution. This information should therefore be used as a guide only. Applicable module, area, length, diameter and MWCO were obtained from ITT PCI Membranes Ltd manuals

${ }^{\mathrm{b}}$ Pore size info were obtained from the other two mentioned sources in the table caption

Table 7 Characteristics and specifications of the four commercial membrane types (SOLTEQ Company: Solution Engineering 2008; ITT PCI Membranes Ltd 2011; Perry and Green 1999; McCabe et al. 1993; Geankoplis 2003)

\begin{tabular}{llllll}
\hline$\#$ & Type of membrane & Material & Max. pH range & $\begin{array}{l}\text { Max. pres- } \\
\text { sure (bar) }\end{array}$ & $\begin{array}{l}\text { Appli- } \\
\text { cable } \\
\text { module }\end{array}$ \\
\hline 1 & FP100 & Polyvinylidene difluoride (PVDF) & $1.5-12$ & 10 & UF \\
2 & ES404 & Polyethersulphone & $1.5-12$ & 30 & NF \\
3 & AFC40 & Polyamide low-pressure film & $1.5-9.5$ & 60 & RO \\
4 & AFC99 & Polyamide high-pressure film & $1.5-12$ & 64 & RO \\
\hline
\end{tabular}

Table 8 Different applied pressure values for the four commercial membrane types

\begin{tabular}{llrrrr}
\hline$\#$ & Type of membrane & \multicolumn{4}{c}{ Applied pressure values (bar) } \\
\cline { 3 - 6 } & & P1 & P2 & P3 & P4 \\
\hline 1 & FP100 & 4 & 6 & 8 & 10 \\
2 & ES404 & 5 & 10 & 20 & 30 \\
3 & AFC40 & 30 & 40 & 50 & 60 \\
4 & AFC99 & 34 & 44 & 54 & 64 \\
\hline
\end{tabular}

were similar to the composition of Red Sea at Jeddah which was reported elsewhere in a previous work and as shown in Table 5 (Greenlee et al. 2009; Lenntech 2005). The feed conductivity was 54 milli-Siemens $/ \mathrm{cm}(\mathrm{mS} / \mathrm{cm})$ and about $8 \mathrm{pH}$. The experiment work included four commercial membranes that have been utilized to identify the ideal membrane type for the treatment of the Red Sea water. The used commercial membranes physical properties and specs are shown in Tables 6 and 7, respectively.

The work was initiated by applying different pressure values on the used four commercial membranes (FP100, ES404, AFC40 and AFC99), as tabulated in Table 8, in order to determine the optimal operating pressure for the treatment of the Red Sea water. Figure 4 shows a picture of the membrane filtration test unit (Model: TR 14) that was used for the experiment work. Procedure and desired operating conditions of each membrane type from Table 9 as well as the membrane filtration test unit process flow diagram from Fig. 5 show the exact technique to perform the experiment work (SOLTEQ Company: Solution Engineering 2008; ITT PCI Membranes Ltd 2011).

For each membrane type experiment, Tank 1 was filled up periodically with $15 \mathrm{~L}$ of Red Sea water at room temperature $\left(27^{\circ} \mathrm{C}\right)$. The feed tank (Tank 1$)$ water level was fixed with a level control to maintain the experimental work. Sensors and indicators including temperature transmitters, pressure indicators and flow transmitters were checked properly before starting the experiments to ensure correct results. Open and closed valves plus valve connections have been investigated and applied for each membrane type experiment as described in Table 9. After that, the pump was operated to apply pressure on the membrane module at four different set points on each membrane, as shown in Table 8, where the seawater was passed through each membrane type separately. A pressure gauge was used to control the pressure increase from one experiment to the other. The system was operated for a short time (1-2 $\mathrm{min}$ ) in order to take the required water samples for further studies in which water samples were measured to determine the conductivity and $\mathrm{pH}$ values. A sample of the tubular membrane used in the membrane filtration test unit is shown in Fig. 6.

Moreover, $\mathrm{pH}$ readings have been considered in the experimental results to study the relation between the different applied pressures and $\mathrm{pH}$ values $(\mathrm{pH}$ is dependent on water conductivities since conductivities are attributed to applied pressure). A comparison between the four membranes was established to select the ideal membrane at a specific operating pressure for the treatment. 


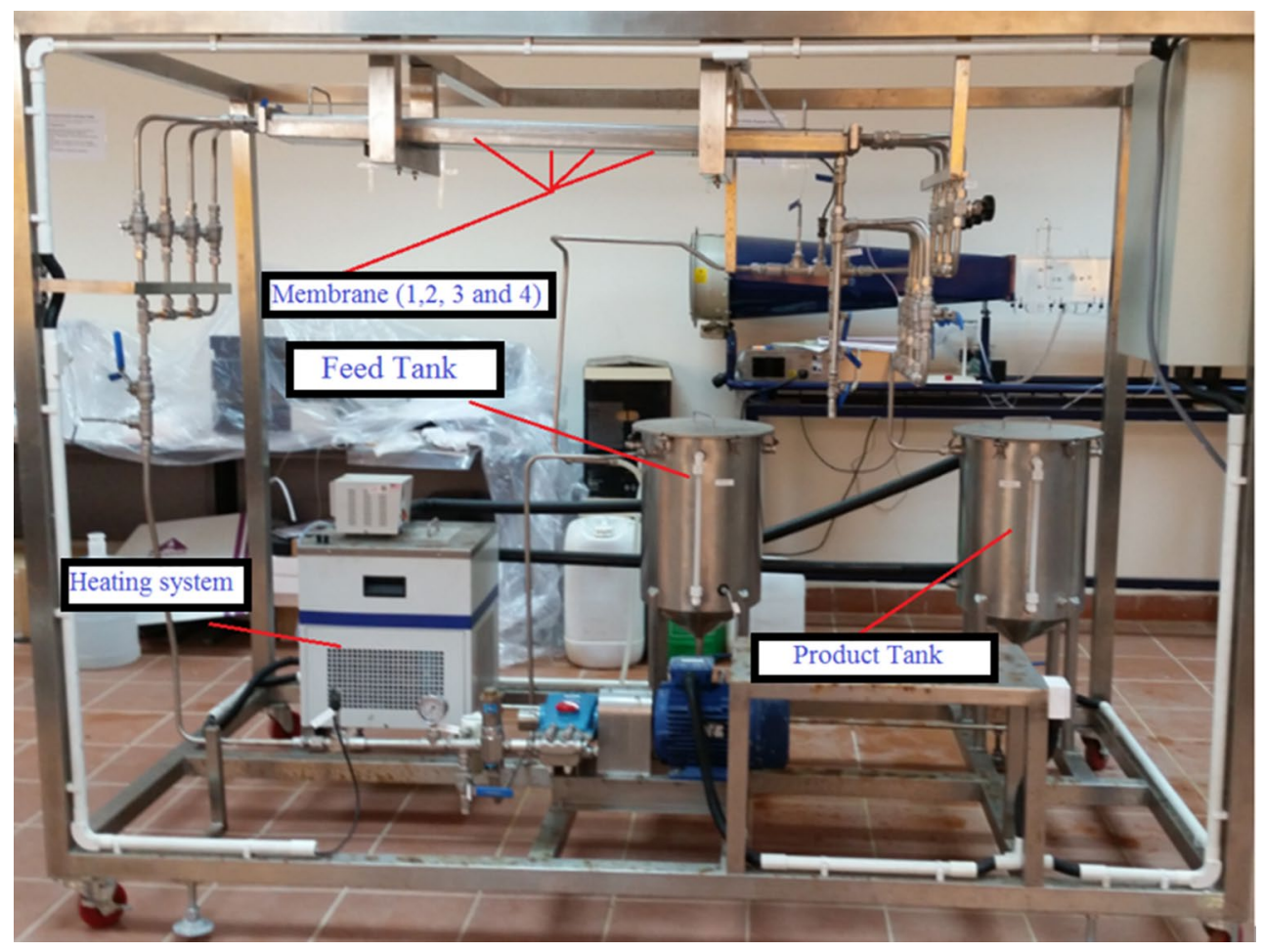

Fig. 4 The membrane filtration test unit; Model: TR 14

Table 9 Procedure and desired operating conditions for the four commercial membrane types (SOLTEQ Company: Solution Engineering 2008; ITT PCI Membranes Ltd 2011; Perry and Green 1999; McCabe et al. 1993; Geankoplis 2003)

\begin{tabular}{llllll}
\hline \# & Type of membrane & Open valves & Sampling valves & $\begin{array}{l}\text { Retentate } \\
\text { control } \\
\text { valve }\end{array}$ & $\begin{array}{l}\text { Membrane maximum } \\
\text { inlet pressure (bar) }\end{array}$ \\
\hline 1 & FP100 & V2, V6, V7, V11 and V15 & Sampling 1 & V15 & 10 \\
2 & ES404 & V2, V6, V8, V12 and V16 & Sampling 2 & V16 & 30 \\
3 & AFC40 & V2, V6, V9, V13 and V17 & Sampling 3 & V17 & 60 \\
4 & AFC99 & V2, V6, V10, V14 and V18 & Sampling 4 & V18 & 64 \\
\hline
\end{tabular}

Equation (4) was used to calculate the exact removal percentage (treatment efficiency) of each membrane type from the water samples besides their initial and final conductivities (Perry and Green 1999).

$\mathbb{R}=\frac{C_{\mathrm{i}}-C_{\mathrm{o}}}{C_{\mathrm{i}}} \times 100$

where $\mathbb{R}$, Seawater membrane removal percentage, $\% ; C_{\mathrm{i}}$, seawater inlet conductivity, feed, $\mathrm{mS} / \mathrm{cm} ; C_{0}$, seawater outlet conductivity, product, $\mathrm{mS} / \mathrm{cm}$

\section{Results and discussion}

\section{Effect of pressure on produced water conductivity}

Results showed that the optimal operating pressures for the four membranes FP100, ES404, AFC40 and AFC99 were
10, 30, 60 and 64 bar, respectively. Figures 7, 8, 9 and 10 show the effect of the applied pressure of the various commercial membranes FP100, ES404, AFC40 and AFC99 on the water conductivity. The overall investigation concluded that as the applied pressure increased, the water conductivity decreased; which indicated an inverse correlation between pressure and conductivity.

Figure 7 shows that treated water conductivity decreased to $51 \mathrm{mS} / \mathrm{cm}$ linearly as the applied pressure increased which is logical because high pressures means more force applied on FP100 membrane surface which would shrink membrane pores and as a result more salts were captured. Also, ES404 in Fig. 8 followed an almost linear relationship between treated water conductivity and applied pressure with a final conductivity of $49.5 \mathrm{mS} / \mathrm{cm}$. Contrary to what was expected, conductivity increased at $10 \mathrm{bar}$ which might be attributed to accumulation of salts on ES404 membrane surface from the first experiment at 5 bar; and then the following experiments 


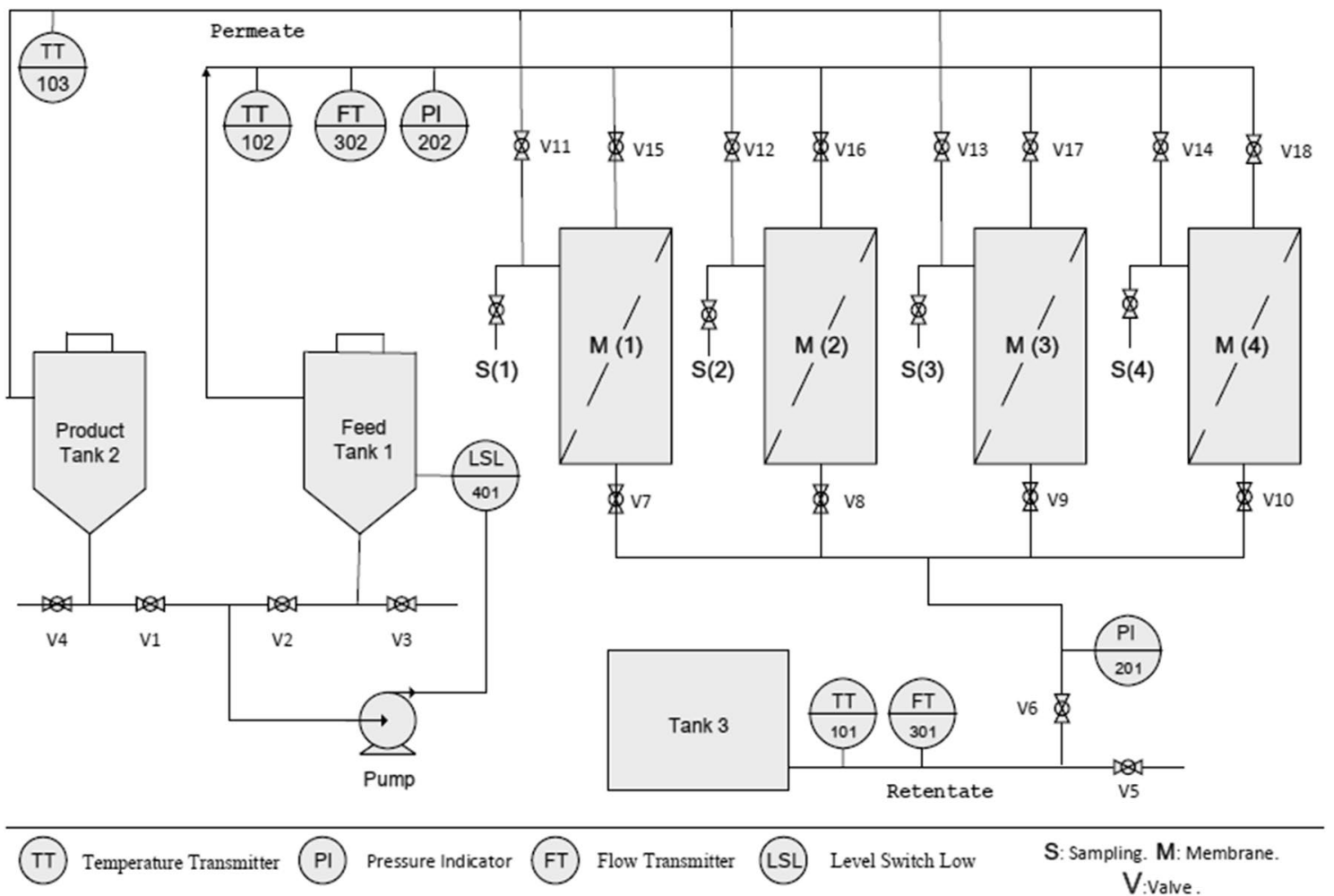

Fig. 5 Process flow diagram of the membrane filtration test unit; model: TR 14 (SOLTEQ Company: Solution Engineering 2008 and ITT PCI Membranes Ltd 2011)

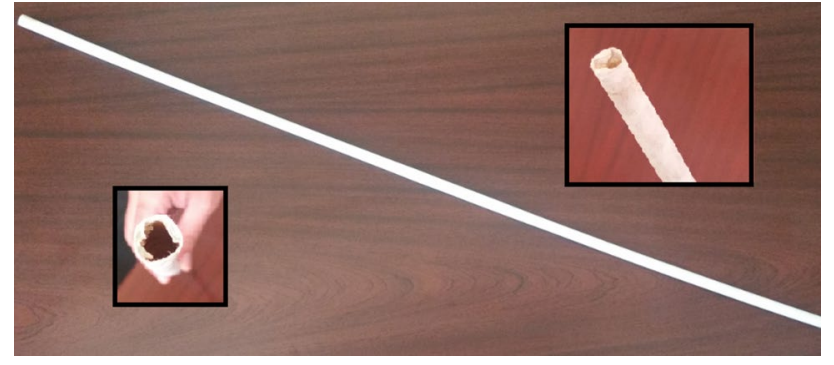

Fig. 6 Sample of the tubular membrane used in the membrane filtration test unit; model: TR 14

at 20 and 30 bars decreased conductivity again which might confirm our analysis. Similar observations were recorded in Figs. 9 and 10 for the second treatment experiment of AFC40 and AFC99 membranes, respectively, where conductivity increased again due to salt accumulations from the first stage. Again, AFC40 and AFC99 had an almost linear decrease in conductivity with respect to applied pressure and the minimum achieved conductivities were 48 and $44 \mu \mathrm{S} /$ $\mathrm{cm}$, respectively.

In the four studied membranes, the water conductivity decreased sharply, initially, and then reached a plateau due to salt depositions onto membrane surface which

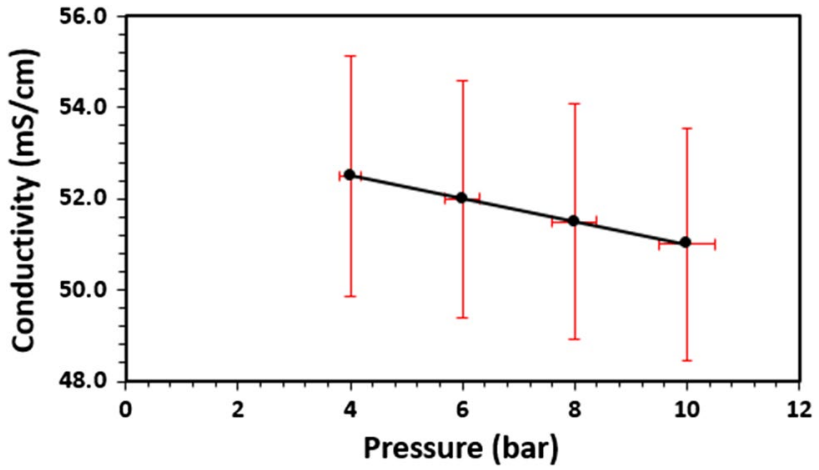

Fig. 7 Effect of different applied pressures on the treatment of the Red Sea water in membrane \#1 (FP100)

restrained further salt rejections. Conductivity results were found as expected since RO membranes are commercially utilized to treat seawater and produce desalinated water by having the outlet water conductivities much less than the inlet conductivities.

\section{Effect of pressure on produced water pH level}

Calcium carbonate $\left(\mathrm{CaCO}_{3}\right)$ salt presents in seawater and it has a very low solubility in water $\left(\mathrm{H}_{2} \mathrm{O}\right) . \mathrm{CaCO}_{3}$ is a fairly 


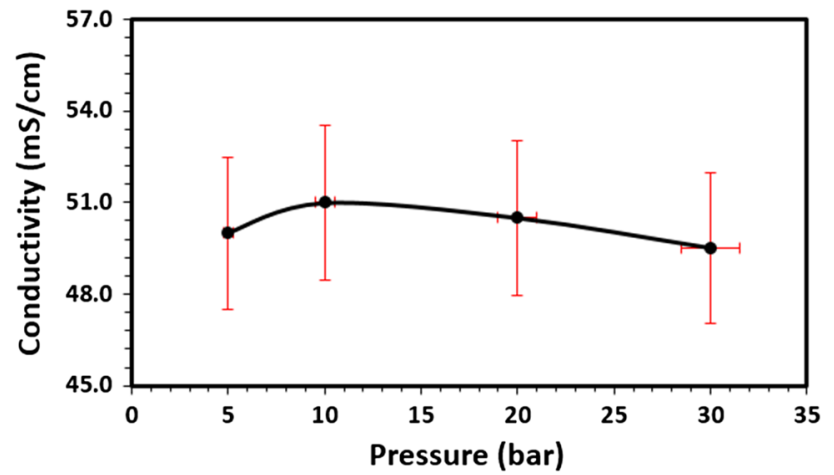

Fig. 8 Effect of different applied pressures on the treatment of the Red Sea water in membrane \#2 (ES404)

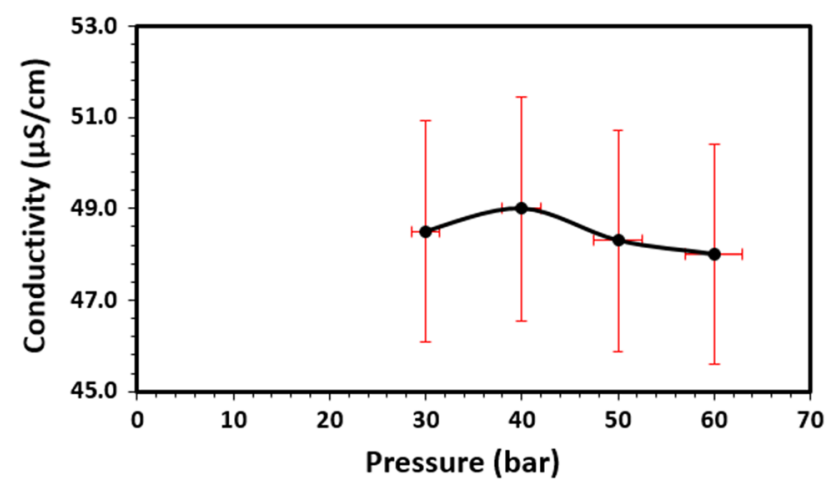

Fig. 9 Effect of different applied pressures on the treatment of the Red Sea water in membrane \#3 (AFC40)

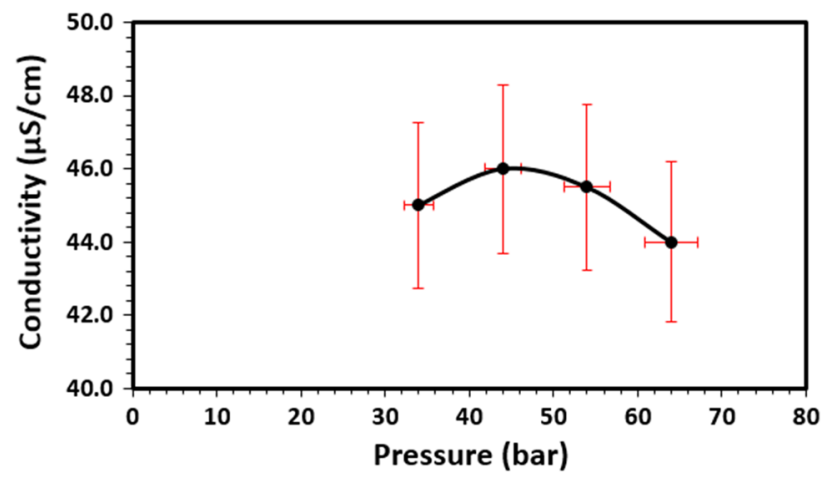

Fig. 10 Effect of different applied pressures on the treatment of the Red Sea water in membrane \#4 (AFC99)

strong base (calcium hydroxide, $\mathrm{Ca}(\mathrm{OH})_{2}$ ) and a weak acid (carbonic acid, $\mathrm{H}_{2} \mathrm{CO}_{3}$ ). In aqueous solution salts undergo hydrolysis to give free $\mathrm{OH}^{-}$ions, and so the solution will be basic. However, since $\mathrm{CaCO}_{3}$ is slightly soluble in water, the $\mathrm{pH}$ of the water should be above 7 and therefore $\mathrm{CaCO}_{3}$ could be responsible for the increase in the water basicity. A high alkalinity in seawater is usually caused by high concentrations of carbonates such as $\left(\mathrm{CaCO}_{3}\right)$, magnesium

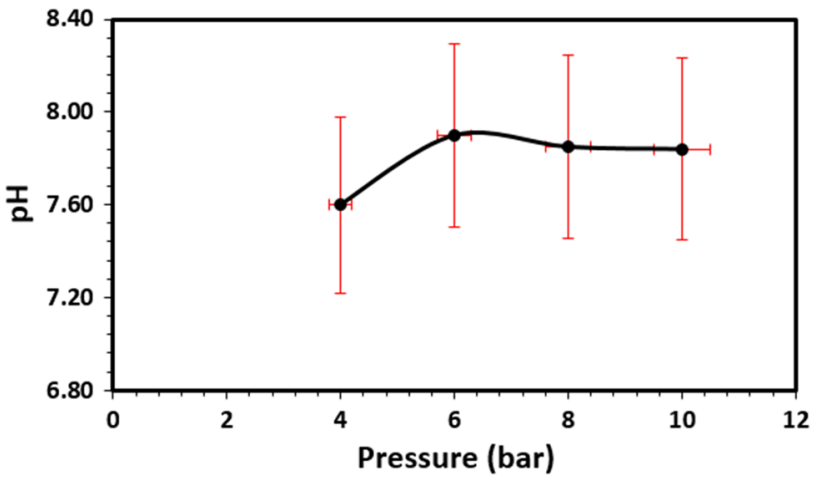

Fig. 11 Effect of different applied pressures on the $\mathrm{pH}$ value of the Red Sea water in membrane \#1 (FP100)

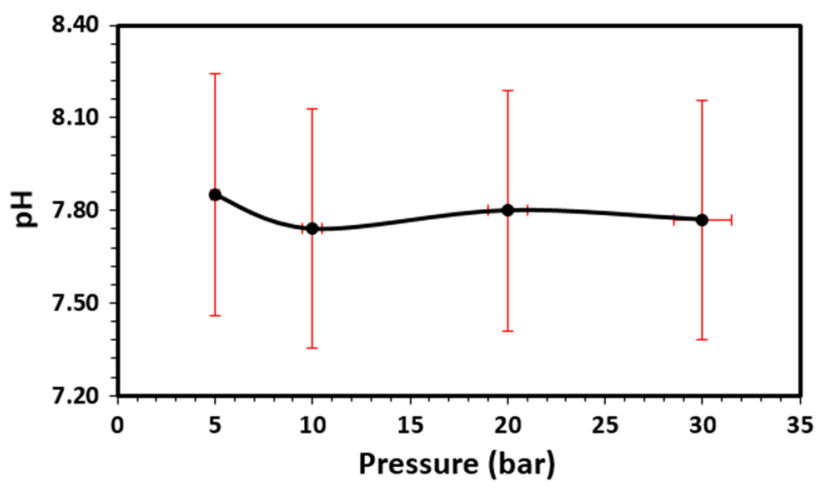

Fig. 12 Effect of different applied pressures on the $\mathrm{pH}$ value of the Red Sea water in membrane \#2 (ES404)

carbonate $\left(\mathrm{MgCO}_{3}\right)$ and bicarbonates $\left(\mathrm{HCO}_{3}{ }^{-}\right) \cdot \mathrm{pH}$ is a measure of the acidity and basicity of seawater. Since $\mathrm{CaCO}_{3}$ particle size is $\leq 30$ or $1.5-20 \mu \mathrm{m}$, one may infer that the four studied membranes would capture $\mathrm{CaCO}_{3}$ salt particles from feed water and a reduced product water basicity (lower $\mathrm{pH}$ ) should be observed. In other words, UF, NF and RO membranes are capable of removing $\mathrm{CaCO}_{3}$ salts from seawater (Greenhouse 2012; Zheng and Vinson 2014; TETRA Technologies Inc. 2015; Soria 2010).

Figures 11, 12, 13 and 14 show the effect of the applied pressure of the various commercial membranes FP100, ES404, AFC40 and AFC99 on the water pH. In all membranes, very slight changes in $\mathrm{pH}$ were noted and $\mathrm{pH}$ level decreased sharply at the first applied pressure experiment and then started to recover the initial $\mathrm{pH}$ level at further stages. The initial decrease in $\mathrm{pH}$ levels was attributed to the rejections of $\mathrm{CaCO}_{3}$ salts from seawater which decreases product water basicity. However, successive experiments at higher pressures may force accumulated $\mathrm{CaCO}_{3}$ salts on the membrane surface to go through and recover $\mathrm{pH}$ level (increase water basicity) in later stages. 


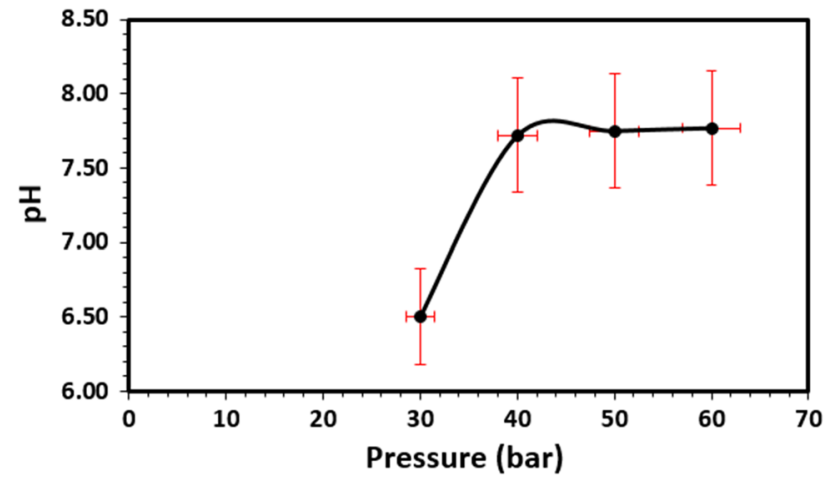

Fig. 13 Effect of different applied pressures on the $\mathrm{pH}$ value of the Red Sea water in membrane \#3 (AFC40)

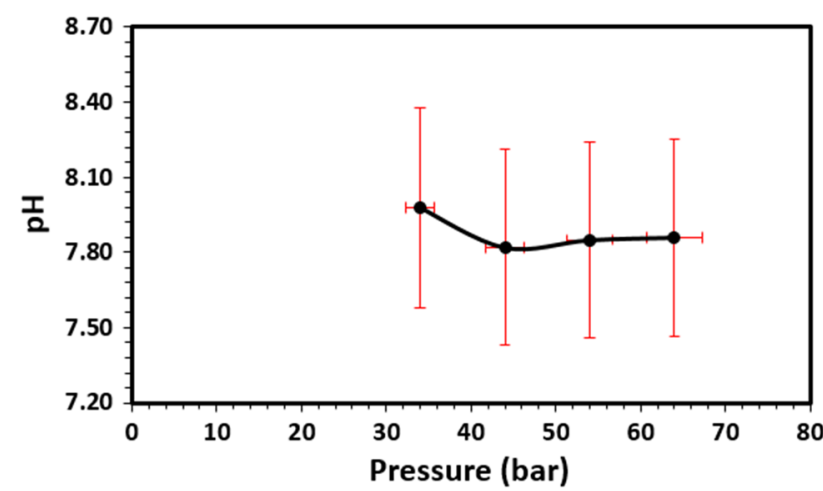

Fig. 14 Effect of different applied pressures on the $\mathrm{pH}$ value of the Red Sea water in membrane \#4 (AFC99)

Figures 11 and 13 showed the $\mathrm{pH}$ behavior in FP100 and AFC40, respectively, which decreased initially with the applied pressure due to the removal of $\mathrm{CaCO}_{3}$ and then recovered to a magnitude about the initial $\mathrm{pH}$. However, Figs. 12 and 14, showed lower $\mathrm{pH}$ recovery at higher applied pressure. As noted previously, $\mathrm{pH}$ recovery occurred in further stages because of passing of accumulated $\mathrm{CaCO}_{3}$ salts across the membrane when treating seawater at higher pressures. The overall investigation concluded that there was a slight proportional relationship between $\mathrm{pH}$ and pressure taking into consideration that the initial sudden $\mathrm{pH}$ decrease in ES404 and AFC99 extended for the first two pressure experiments.

The final water product conductivity and $\mathrm{pH}$ for each of the four commercial membranes FP100, ES404, AFC40 and AFC99 has been measured as reported in Table 10. To ease the calculations, the applied pressure that is related to the previous results was determined by taking the average of the four different applied pressure values of each membrane type. Obviously, we have an inverse relationship between applied pressure and water conductivity. On the contrary, $\mathrm{pH}$
Table 10 Characteristics of the water product for the four commercial membranes at their averaged pressure values

\begin{tabular}{lllll}
\hline$\#$ & Type of membrane & $\begin{array}{l}\text { Average } \\
\text { pressure } \\
\text { (bar) }\end{array}$ & Sample conductivity & $\mathrm{pH}$ \\
\hline 1 & FP100 & 7 & $49.7 \mathrm{mS} / \mathrm{cm}$ & 7.74 \\
2 & ES404 & 16.25 & $48.3 \mathrm{mS} / \mathrm{cm}$ & 7.78 \\
3 & AFC40 & 45 & $47.5 \mu \mathrm{S} / \mathrm{cm}$ & 7.75 \\
4 & AFC99 & 49 & $42.5 \mu \mathrm{S} / \mathrm{cm}$ & 7.82 \\
\hline
\end{tabular}

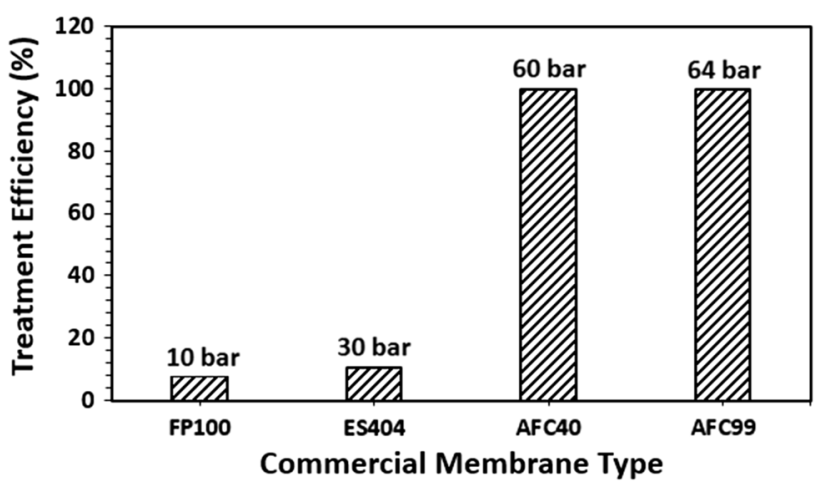

Fig. 15 The overall treatment efficiency of the four commercial membranes for the Red Sea water

levels slightly decrease when decreasing the applied pressure; the variations of $\mathrm{pH}$ with pressure are very low and this could fall into the error percentage as shown in Figs. 11, 12,13 and 14 .

The calculated overall treatment efficiency for the final water product of the four commercial membranes FP100, ES404, AFC40 and AFC99 were 8, 10.6, 99.9 and 99.9\%, respectively, as shown in Fig. 15. Therefore, AFC40 and AFC99 showed the maximum treatment efficiency for the Red Sea water. Yet, based on the energy demand, AFC40 should be operated at an applied pressure that is 4 bar less than AFC99 (from the manual data as shown in Table 8); hence, AFC40 is the ideal membrane choice due to its lower energy demand.

\section{Surface morphology}

During the process of impurities removal, membranes will inevitably encounter the membrane fouling induced by micro-particles and their combination with organic matters in seawater as shown in Fig. 16a-h. It can be noticed that we had various impurities with different particles size on the membrane surface which is respective to membrane pore size. Larger particles size on the surface of FP100, ES404 and AFC40 were found and compared to the smaller particles on AFC99. This can be attributed 

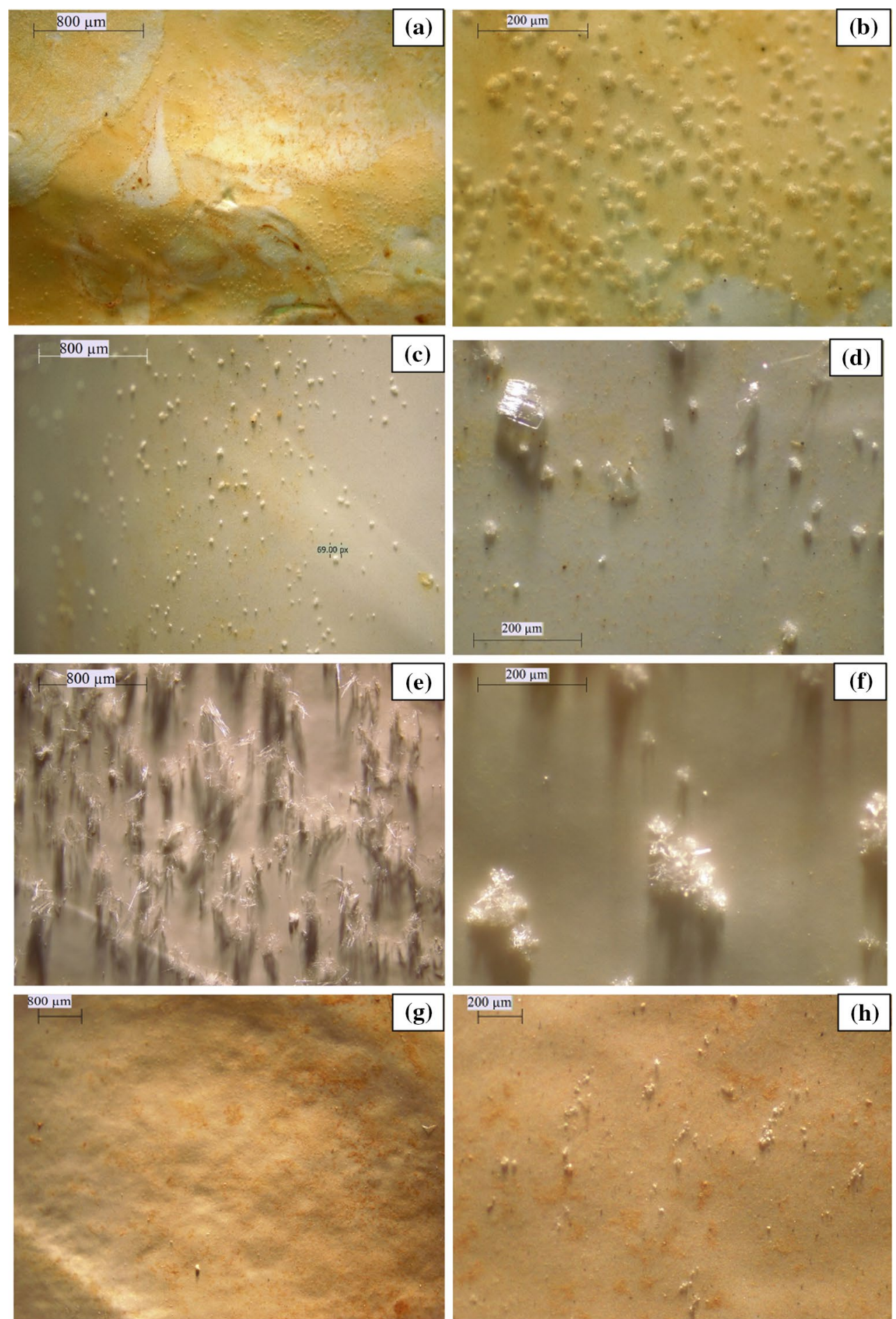

Fig. 16 Optical images of impurities stained with fouling layer formed on a, b Polyvinylidene difluoride or PVDF (FP100), c, d Polyethersulphone (ES404), e, f Polyamide low-pressure film (AFC40) and g, h Polyamide high-pressure Film (AFC99)

to the large pores of the three membranes compared to AFC99. Despite that AFC40 and AFC99 are both with the same pore size (RO membranes), contribution of the high-pressure operation on AFC99 might be responsible for the decomposition of large particles into smaller ones as shown in Fig. $16 \mathrm{~g}$, h.

The authors suggest that the yellowish color appeared in Fig. 16a, b, g, h might be attributed to the presence of dissolved irons as $\mathrm{Fe}(\mathrm{OH})_{2}^{+}$in the collected water. Seawater 
contains approximately 1-3 ppb of iron and most algae in seawater contain between 20 and $200 \mathrm{ppm}$ of iron, and some brown algae may accumulate up to 4000 ppm (Murphy et al. 1976). Iron has a silver color, but when both water and oxygen are present iron corrodes and changes to a yellowish color due to the formed hydrated oxides.

Fouling issue will decrease the life-time of the membranes and therefore regular flush and/or backwash is required to maintain the quality of the membranes. It is recommended to perform a low pressure flush with deionized feed water to remove concentrate from $\mathrm{RO}$ and $\mathrm{NF}$ membranes surface (ES404, AFC40 and AFC99). Also, a regular backwash with air scour should be conducted for UF membranes (FP100) to remove foulants. Commercial membranes life-time varies between 2 and 3 years for $\mathrm{RO} /$ $\mathrm{NF}$ and $3-5$ years for UF deepening on operating conditions, flux rates and cleaning intervals.

Estimated water flux has been calculated experimentally from the known membrane area, feed water volume and treatment time. Feed water fluxes varied between 4 and $11.1 \mathrm{~L} / \mathrm{m}^{2} \mathrm{~min}$ as obtained from filtration experiments. However, permeate water flux data were not available, but the authors believe that values of the permeate flux should be close to the feed flux depending on the membrane resistance to the coming flow.

\section{Conclusion}

Treatment efficiency has been investigated for several commercial membrane modules (FP100, ES404, AFC40 and AFC99) by studying the effect of the applied pressure on the Red Sea water conductivities at Rabigh. Also, pH levels of produced water were analyzed to check the effect of different applied pressures on $\mathrm{pH}$ variations. The Red Sea water samples that were used as a feed had a conductivity of $54 \mathrm{mS} / \mathrm{cm}$ and a pH of 8 . The ultimate goal was to identify the ideal membrane type for the treatment of the Red Sea water among the four commercial membranes with its optimum pressure.

Results showed that the optimal operating pressures for the four commercial membranes FP100, ES404, AFC40 and AFC99 were 10, 30, 60 and 64 bar, respectively. It is suggested that applying higher pressures would increase the treatment efficiency in the four commercial membranes. An inverse relationship was identified between water conductivity and applied pressure, and $\mathrm{pH}$ levels slightly decreased at high pressures.

Our findings confirmed that AFC40 is the ideal membrane choice among other commercial membranes for the treatment of the Red Sea water because of the high treatment efficiency of $99.9 \%$ and the lower energy demand (AFC40 operating pressure is 4 bar less than AFC99) which might be a promising result for water treatment plants.

\section{Compliance with ethical standards}

Conflict of interest The authors that they have no conflict of interest to declare.

Open Access This article is distributed under the terms of the Creative Commons Attribution 4.0 International License (http://creativeco mmons.org/licenses/by/4.0/), which permits unrestricted use, distribution, and reproduction in any medium, provided you give appropriate credit to the original author(s) and the source, provide a link to the Creative Commons license, and indicate if changes were made.

\section{References}

Ahunbay MG, Tantekin-Ersolmaz SB, Krantz WB (2018) Energy optimization of a multistage reverse osmosis process for seawater desalination. Desalination 429:1-11

Alawadhi AA (2002) Regional report on desalination-GCC countries. In: Proceedings of the IDA World Congress on desalination and water reuse, Manama, Bahrain, vol 8, p 13

Al-Badawi A, Al-Harthi SS, Imai H, Iwahashi H, Katsube M, Fujiwara N (1995) Operation and analysis of Jeddah 1-Phase II plant. In: Proceedings of the IDA and World Congress on desalination and water sciences, Abu Dhabi, United Arab Emirates, vol 3, pp 41-54

Alzahrani S, Mohammad AW, Hilal N, Abdullah P, Jaafar O (2013) Comparative study of NF and RO membranes in the treatment of produced water-part I: assessing water quality. Desalination 315:18-26

Ayyash Y, Imai H, Yamada T, Fukuda T, Yanaga Y, Taniyama T (1994) Performance of reverse osmosis membrane in Jeddah Phase I plant. Desalination 96(1):215-224

Badrulla Baig M, Kutbi A, Aziz A (1999) Design features of a 20 migd SWRO desalination plant, Al Jubail, Saudi Arabia. Water Supply 17(1):127-134

Charcosset C (2009) A review of membrane processes and renewable energies for desalination. Desalination 245(1-3):214-231

Drioli E, Criscuoli A, Curcio E (2002) Integrated membrane operations for seawater desalination. Desalination 147(1):77-81

Emis: energie-en milieu-informatiesysteem voor het Vlaamse Gewes (2010) Microfiltration. Boeretang

EPA N (2005) Membrane filtration guidance manual. EPA 815-R-06009, Office of Water, Washington

Fane AG (1996) Membranes for water production and wastewater reuse. Desalination 106(1):1-9

GEA Process Engineering Inc (2012) Membrane filtration: reverse osmosis, nanofiltration. Ultrafiltration and Microfiltration, Hudson

Geankoplis C (2003) Transport processes and separation process principles (includes unit operations). Prentice Hall Press, Englewood Cliffs

Greenhouse and Nursery Water Treatment Information System (2012) Membrane filtration. School of Environmental Sciences, University of Guelph, Guelph

Greenlee LF, Lawler DF, Freeman BD, Marrot B, Moulin P (2009) Reverse osmosis desalination: water sources, technology, and today's challenges. Water Res 43(9):2317-2348

Humplik T, Lee J, O'hern SC, Fellman BA, Baig MA, Hassan SF, Atieh MA, Rahman F, Laoui T, Karnik R, Wang EN (2011) 
Nanostructured materials for water desalination. Nanotechnology 22(29):292001

Inventory ID (2004) Desalination business stabilized on a high level. Int Desal Water Reuse 14(2):14-17

Khawaji AD, Kutubkhanah IK, Wie JM (2008) Advances in seawater desalination technologies. Desalination 221(1):47-69

Khaydarov RA, Khaydarov RR (2007) Solar powered direct osmosis desalination. Desalination 217(1-3):225-232

Khulbe KC, Feng CY, Matsuura T (2007) Synthetic polymeric membranes: characterization by atomic force microscopy. Springer, Berlin, chap. 7, section 7.1, p 161

Lenntech (2005) Composition of seawater: major ion composition of seawater (mg/L). https://www.lenntech.com/composition-seawa ter.htm. Accessed on 20 Dec 2017

ITT PCI Membranes Ltd (2011) TP78_25 Membranes and Modules: Membrane Information. Basingstoke, United Kingdom. http:// www.christianberner.se/\$-1/file/leverantorer/pci-membranes/ dokument/membranfilter.pdf. Accessed on 10 Aug 2016

Maddah HA, Chogle AM (2015) Applicability of low pressure membranes for wastewater treatment with cost study analyses. Membr Water Treat 6(6):477-488

Maddah H, Chogle A (2017) Biofouling in reverse osmosis: phenomena, monitoring, controlling and remediation. Appl Water Sci 7(6):2637-2651

Malek A, Hawlader MNA, Ho JC (1996) Design and economics of RO seawater desalination. Desalination 105(3):245-261

McCabe WL, Smith JC, Harriott P (1993) Unit operations of chemical engineering, vol 5. McGraw-Hill, New York, p 154

Murphy TP, Lean DR, Nalewajko C (1976) Blue-green algae: their excretion of iron-selective chelators enables them to dominate other algae. Science 192(4242):900-902

Nada N, Yanaga Y, Serizawa S, Tanaka K (1995) Design features of the largest SWRO plant in the world-33.8 MGD in Madina and Yanbu. In: Proceedings of the IDA and World Congress on desalination and water sciences, Abu Dhabi, United Arab Emirates, vol 5 , pp 3-15

National Environmental Services Center (1999) Membrane filtration: a national drinking water clearinghouse fact sheet. Retrieved from http://www.nesc.wvu.edu/pdf/dw/publications/ontap/2009_ tb/membrane_DWFSOM43.pdf

Otero JA, Mazarrasa O, Villasante J, Silva V, Prádanos P, Calvo JI, Hernández A (2008) Three independent ways to obtain information on pore size distributions of nanofiltration membranes. $J$ Membr Sci 309(1):17-27
Ozaki H, Li H (2002) Rejection of organic compounds by ultra-low pressure reverse osmosis membrane. Water Res 36(1):123-130

Perry RH, Green DW (1999) Perry's chemical engineers' handbook. McGraw-Hill Professional, New York

Profile M (2006) Desalination Markets 2007 preview. Global Water Intelligence, $\mathrm{p} 27$

Rajamohan R, Venugopalan VP, Debasis M, Usha N (2014) Efficiency of reverse osmosis in removal of total organic carbon and trihalomethane from drinking water. Res J Chem Environ 18:1-6

Sagle A, Freeman B (2004) Fundamentals of membranes for water treatment. Future Desalination Tex 2:137-154

Smart Membrane Solutions (2002) Membrane classifications: reverse osmosis, nanofiltration. Ultrafiltration and Microfiltration, Rolleston

SOLTEQ Company: Solution Engineering SDN. BHD (2008) Experimental manual, membrane test unit, model: TR 14. Puchong

TETRA Technologies Inc. (2015). Calcium carbonate bridging agents: PayZoneCarb Ultra. The Woodlands

Truby R (2000) Water \& Wastewater Int 15 (3) 2000 in Drioli E, Criscuoli A, Curcio E (2002) Integrated membrane operations for seawater desalination, 77-81

Van der Bruggen B, Vandecasteele C (2002) Distillation vs. membrane filtration: overview of process evolutions in seawater desalination. Desalination 143(3):207-218

Wade NM (1993) Technical and economic evaluation of distillation and reverse osmosis desalination processes. Desalination 93(1-3):343-363

Wagner J (2001) Membrane filtration handbook-practical tips and hints. Osmonics. Inc., Minnetonka

Wijmans JG, Baker RW (1995) The solution-diffusion model: a review. J Membr Sci 107(1):1-21

Williams M, Deshmukh R, Bhattacharyya D (1990) Separation of hazardous organics by reverse osmosis membranes. Environ Prog Sustain Energy 9(2):118-125

Yoon Y, Lueptow RM (2005) Removal of organic contaminants by RO and NF membranes. J Membr Sci 261(1):76-86

Zheng Y, Vinson K (2014) pH control: acidification of irrigation water. School of Environmental Sciences, University of Guelph, Guelph

Publisher's Note Springer Nature remains neutral with regard to jurisdictional claims in published maps and institutional affiliations. 